\title{
Ngugi wa Thiong'o' Cosmogenic Meta-Myth in The Perfect Nine: The Epic of Gikuyu and Mumbi (Kenda Muiyuri: Rugano Rwa Gikuyu Na Mumbi)
}

\author{
Njogu Waita* \\ Department of Humanities, Chuka University P.O. Box 109-60400mChuka
}

*Corresponding Authors: Njogu Waita, Department of Humanities, Chuka University P.O. Box 109$60400 m$ Chuka

\begin{abstract}
This study seeks to review, analyse and evaluate the presentation of the Kikuyu myth of origin as presented in Ngugi Wa Thiong'o's narrative verse; Kenda Muiyuru: Rugano Rwa Gikuyu na Mumbi(The Perfect Nine: The Epic of Gikuyu and Mumbi.). The study is primarily a critical textual analyses of the author's original publication in Gikuyu language, but also refers to oral traditions and oral literature of the Kikuyu people. The paper critics the mythic formation of the Kikuyu nation through the ten ('perfect nine') daughters and explores symbolic significance of the journey motif exploited by the writer in this version of narrating the Kikuyu nation. The study further explores how Ngugi Wa Thiong'o's rendition is a metaphor for an African renaissance that can only be achieved by retracing the steps to the beginning (origin). The return to the primordial times, travelling the road of the fore fathers may occasion the understanding of the current African space and time. This will eventually lead to recreation of a stable and just Africa ridded off the jinx of colonial ogres of cultural and economic domination. In the process, the study explores Ngugi Wa Thiong'o's ultimate romantic feminist vision that proposes gender equity as the base for the creation of a stable self-sustaining and prosperous society.
\end{abstract}

\section{INTRODUCTION}

Cosmogenic myths set the pattern for everything else in the world. The mythic narrative constructs the story of our origins by transcending the limits of ordinary human perception and reason. Nevertheless, the mythic narrative form the bases and the beginning of all thinking including scientific thought. The cosmos generated in the mythic narrative is primarily the world of man and woman. They are brought forth into the cosmos to be the namers and moulders of the creation, and the world to become the abode for their descendants. This paper seeks to review, analyse and evaluate the presentation of the Kikuyu myth of origin as presented by Ngugi wa Thiong'o in his narrative in verse; Kenda Muiyuru: Rugano Rwa Gikuyu Na Mumbi (The Perfect Nine: The Epic of Gikuyu and Mumbi).

The Kikuyu people today number over eight million, and are scattered all over Kenya but primarily live in Kirinyaga, Nyeri, Nyandarua, Murang'a and Kiambu counties in the Mount Kenya region of Kenya. The Kikuyu country is dominated by Mount Kenya, which rises to 5,199 metres above the sea level and the Aberdare range of mountains, which also rises to over 3,999 metres above sea level. The permanently snow covered peaks of Mt. Kenya are revered as the abode of the Kikuyu God, Ngai, Murungu, Mwene Nyaga. The Kikuyu speak a Bantu language with at least five discernible dialects among the people who refer to themselves as Kikuyu. These include Kabete-Metumi, Gaki, Mathira, Ndia and Gichugu dialects. Culturally and linguistically the Kikuyu are closely related to Embu, Mbeere and Meru speakers. These communities have been classified as the Thagichu speakers (Mutahi: 1977, Muriuki: 1974:57-58, Castro: 1995:19).

The Cosmogenic myth of the Kikuyu is the story of Gikuyu and Mumbi and of their ten daughters (Full Nine (Kenda Muiyuru). Tradition has it that God gave Gikuyu and Mumbi the land on the slopes of Mt. Kenya where they settled and were blessed with the daughters. God provided nine suitors for the daughters, after Gikuyu sacrificed to Him and these men agreed to marry the daughters and live on 
the land bequeathed to the daughters under a matriarchal system (Kenyatta: 1938:) From each of these daughters arises the nine clans named after them. The tenth clan that brings up the total to the 'full nine' is the Aicakamuyu, begotten of the last born daughter, Warigia, who is said to have become pregnant outside wedlock and never got married.

Historical sources highlight the formation of the nine clans as the final consolidation of migratory groups that settled on the southern slopes of Mount Kenya from the Rupingazi River in the East to beyond Chania River in the South. These people are today known as Kikuyu. As they are today they consist of a fusion of different peoples who migrated to the region from different regions at different periods for different reasons.

The original Kikuyus are said to be descendants of Thagicu and Igembe peoples who migrated from the current northern Meru County region and started settling in the southern and western slopes Mount Kenya region as early as the $12^{\text {th }}$ century. The different splinter groups scattered from the Ithanga hills, currently in Machakos County, settling in the current Kirinyaga, Murang'a and Nyeri Counties. They continuously moved southward to Kiambu County in the late $18^{\text {th }}$ and early $19^{\text {th }}$ centuries. Other groups that infused and became part of the Kikuyu include Kamba, Ukavi, Maasai and Ndigirigi peoples as well as original inhabitants of the region; the Gumba and the Athi. The Athi are also known as Ogiek or Ndorobo.

As recently as the beginning of the Twentieth Century, Kikuyu clans claimed descent from other communities. The Anjiru and Aicakamuyu clans claimed descent from Chuka, the Agachiku and Aceera from the Kamba and the Amboi and Aithekahuno from the Maasai, while Ethaga claimed to have migrated from Mount Kilimanjaro region. (Macgregor:1909,Dundas 1908: 137, Lambert: 1956.Muriuki: 1974)

In Ngugi Wa Thiong'o's text, we have a the linguistic pointer of the origin of Kikuyu as to the east (Thagicu, Igembe and Chuka). This is exhibited in the traditional Kikuyu way of expressing surprise or awe by shouting the clan name, prefixed with the expression Abo. For instance the Anjiru clan when awed, surprised or reconciling within the clan would exclaim, 'abo Njiru... tweherie mburagano (lets maintain peace and harmony)' ( $\mathrm{p}$ 14-15). The phonetic output of the first and the last words (abo and mburagano) is akin to sound patterns of the same words in the current spoken Gi-Chuka dialect. Ngugi Wa Thiong'o acknowledges this similarity noting that, the language and culture of the socalled Mount Kenya Peoples- the Kikuyu, Ndia, Gichugu, Embu, Mbere, Chuka, Tharaka. Thagicu Meru and Kamba share many similarities. (pp.vi). Today the nine Kikuyu clans are symbolic rather than a filial representation of the lateral identities. These clans are evident all the way from Chuka to the Kabete in Southern Kiambu.

\section{Gikuyu, Mumbi And the 'Perfect Nine'}

Ngugi Wa Thiong'o in Kenda Muiyuru, Rugano Rwa Gikuyu Na Mumbi (The Perfect Nine: The Epic of Gikuyu and Mumbi), presents the cosmogenic narrative of the Kikuyu people in a refreshingly new poetic, dramatic and cinematographic rendition. From the outset the narrator assures the reader that what is presented is 'but a revelation', marking it as the authoritative narrative whose fictional fantasy is the unquestionable truth in the myth.In the setting of the story, Gikuyu and Mumbi have been there from the beginnings, migrating in primordial times, during the volcanic formation of the world. Finally they reach the mountains of the moon and miraculously find themselves on the snowy peak of one of the mountains that touched the clouds. And from here they are amazed by the spledour of what they see; the mountains across, the rivers and the wildlife below.

Here they have finally found peace and supplicate to their God in song and thanksgiving after which they descend to the land God has bestowed upon them. Upon descent tired and worn-out, they rest and sleep for nine months. At this point, the poet celebrates God as the eternal universal giver, the God of many names but the same God. He connects the Kikuyu to universal human being in time and space specifically reaching out to the rest of Africa, ancient Egypt, Greece and Israel. For all humanity, 'time is linear but life is circular, all starting with the digit one' which is the beginning of all creation (P. 9-13)

Ngugi Wa Thiong'o's in this text, however, presents an aesthetic and imaginative rendition of the 'nine' daughters and the clans they give rise to. Nevertheless the narrator still alludes to their 
traditional stereotypical attributes but models them to create positive and determined feminists. The nine 'full" are Wanjiru, Wambui, Wanjiku, Wangui, Waithera, Wachera, Wambura, Wairimu, Wangari and Wamuyu. Wanjiru, the mother of the Anjiru clan, is peaceful, obsessed with ownership of land but extremely generous. Wambui, progenitor of the Ambui clan is cunning and weaves her baskets as she counts the stars while Wanjiku, the mother of the Agaciku clan on the other hand is an accomplished farmer, a courageous warrior and a champion medicine person. Wangui, Mother of the Angui clan, is said to have emerged from her mother's womb singing while Waithira, mother of the Aitheraand $u$ clan, is a systematic diligent worker, a problem solver who is fair to all. Wachera, the mother of the Achera clan, visits, but only with and to those who have (ripening bananas). She is also seeker of justice.

Wambura the mother of the Ethaga clan, is a rainmaker, with magical powers that can make a hawk drop dead from the skies or curse away hyenas and foxes back into the forest. Wairimu the mother of the Agathigia clan is a potter like her mother and a smith like her father but beyond that she is an accomplished artist who when need arises 'can appropriate the shadows (images) of other people'. Wangari, the mother of the Angari clan is brave like the leopard and fast in protecting the weak against oppression by the strong. Warigia also known as Wamuyu is the mother of the Aicakamuyu clan. She is rarely mentioned as part of the nine allegedly because she became pregnant out of wedlock. But in Ngugi's text she is an outstanding heroine. Although lame since birth, 'she shoots without missing and her teeth are as white as milk. 'When she laughs even the wild animals laugh (P.20, 56).

She completes the ten-fold siblings of Gikuyu and Mumbi, making up the 'perfect nine' or 'full' nine. All the ten daughters born on the slopes of Mount Kenya, emerge as beautiful, brave and balanced feminists. Their fame spreads far and wide. They attract suitors from all over Africa who follow the great African rivers upstream, traversing the jungle and the hills seeking the famous daughters of the Mountain. At this point in the narrative, the daughters of Gikuyu and Mumbi becomes the confluence of 'Father Africa' in the masculinity of their suitors who arrive from South, North and West Africa.

Finally only ninety nine of the prospective suitors make it to Mount Kirinyaga, to the homestead of Gikuyu and Mumbi at Mukurwewa Nyagathanga. Mukurwewa Nyagathanga is the place where Gikuyu and Mumbi settled after God granted him all the land on the slopes of Mt. Kenya. It is famed the as the original place in the meta-myth, the initial homestead of Gikuyu and Mumbi and from where the dispersal of the Kikuyu people took place. Literary it refers to the place of the mukurwe tree (peacock flower-albiziagummifera) where the Nyagathanga birds, a type of weaverbirds perch. But the term can also refer to the mukurwe tree located at 'the sandy place' (Ithanga), which historians place as the dispersal point of the Kikuyu mentioned earlier. Presently the Mukurwe wa Nyagathanga is in Muranga'a County and has been preserved as a historical and cultural shrine.

The ninety nine suitors outstrip the nine daughters by the power of ten. To select ten for his daughters Gikuyu has to test their resilience, knowledge and skills through a variety of tests. He begins with a demand that those who marry his daughters must be ready to live with him under an endogamy marriage arrangement. Seven of the suitors refuse this condition and go back home. At this stage we can assume that the narrative rejects patriarchy as the preferred social structure and roots for an alternative arrangement. This is revealed in the eventual gender vision of this text.

But the ultimate test, the test that would determine the successful ten suitors is the journey to retrace his (Gikuyu and Mumbi's) steps from the top of the Mountain from where he was given the land by God. They have to trek there and bring back a lump of snow (runyaga) mixed with the icy water from the 'pot of God', a lake up the mountain. But the most challenging task is to bring back the strand of hair at the tip of the tongue of Mwengeca, the notorious and elusive king of the ogres. That strand is the only medicine that can cure Warigia, Gikuyu's last born daughter of her infirmity.

\section{RETRACING THE FOOTSTEPS}

The journey motif, retracing the footsteps of Gikuyu and Mumbi's from the abode of God is used by the poet to present a meta-myth that reflects the conflicts and the struggle against oppositional forces to the creation of a nation. To be part of the nation, the individual and the collective must connect with the God of Kirinyaga, the everlasting and eternal benefactor of the Gikuyu nation. At the very elementary level, the connection is done by facing Mount Kirinyaga during prayer and supplication. Secondly during times of great need, elders must scale the slopes into the Mountain forest in order to 
sacrifice the lamb and the goat without blemish to the God of Kirinyaga. But beyond that, zealots have also been known to scale the mountain to complete their communion with God.

According to popular lore even the great Mau Mau hero, Dedan Kimathi Wa Wachiuri, had to retrace the steps up the mountain in order to reconnect with God and gain wisdom and strength to defeat the colonialist. By retracing the steps, Kimathi seeks the rebirth of a nation that has been destroyed by colonialism. Those then, that seek the hands of the daughters of Gikuyu, must retrace the steps to the 'center of the Kikuyu Universe' to seek integration and consequently provide continuity of the nation symbolized by the permanence of Mount Kirinyaga (Amuka: 1910, Ogunde: 1999:89, Waita: 2019)

Henceforth the omniscient narrator of the story of Gikuyu and Mumbi takes a rest and gives way to the first person narrative voice. At first they take the journey to 'the Mountain of faith' for granted starting off with song and laughter. But soon the taxing and arduous part begins leading to attrition and fall out along the way. Difficult terrain attacking wild animals and insects and even worse human and gender conflict are key barriers to overcome before the team reaches the top of the mountain and scopes the ice and the icy water from the 'pool of God'. It is in the human and gender conflict that the writer continues to emphasize his feminist agenda in this text.

A section of the suitors insist that the women ('the perfect nine') are the source of all problems to the men. Firstly by being attractive and secondly because of their ability to perform culturally labelled 'masculine' roles and tasks without undue effort. The men argue that these abilities are due to the women use of witchcraft and charms and the problem can only be solved by vanquishing them. The author here addresses the old adage of patriarchal ideology that the 'beauty of a woman is listlessness' and the greatest threat to male power. Subjected to feminine charm, man is powerless. In addition, women who seek equality with men and trumpet it in their abilities, are evil and must be brought down (Sanday: 1981:189). But the section of the men antagonistic to the daughters are no match to the arrows directed at them from the tree-tops by the girls. As the arrows rain on them, they hurriedly retreat escaping into the forest and returning from where they came from. The rest proceed and after many months and in gender harmony, a total of thirty reach the foot of the mountain. By the time they scale the mountain to reach the ice and the icy pool of God, only a handful of the men and all the nine daughters remain. They scope the ice and fill in their pots with the icy water in joy, celebrating the achievement of their mission.

\section{THE RETURN}

In their return journey, they have to overcome a series of ogres to get back home. The ogre, Mwengeca, on whose tongues grows the healing strand of hair that can heal Warigia, is the first and the critical challenge. Mwengeca is the chief of the ogres and apparently he is the embodiment of all the other ogres. Collectively they overcome the ogre and procure the healing strand of hair. They then overcome a series of other ogres; the ogre of spitting fire, the ogre of defecation, the ogre of great darkness, the ogre of the basket that never fills up, and the attractive male and female ogres in false bodies.

This encounter is an adaptation that draws heavily from the traditional fantasy of Kikuyu ogre stories. Indeed, according to Wanjiku Kabira some of the narratives were adopted from the performances of renowned oral artist, Wanjira Wa Rukenya from Baricho in Kirinyaga County. (Interview: Daily Nation).Ogre stories in most African traditions and especially in the Kikuyu culture almost always represent the ever-present potential of social destruction due untamed male dominance and unrestrained patriarchal power. The folktale of 'Mwengeca' or 'Mangeca' is one of the most popular ogre tales among the Kikuyu people.In the traditional tale, Mwengeca, who is also the leader or the chief of the ogres, holds the key to the medicine that can cure an affliction affecting a female member of the family that has defied all other medication. The men are afraid to venture into the ogre territory and it's a female heroine who dares to seek the medicine. In the traditional story, the heroine is able, largely through her own effort, to overcome the ogre(s) and procure the healing element. Psychologically, the tale becomes the instrument of female endurance and maturation in the face the possibility of sexual temptation and violation. Ideologically, overcoming and vanquishing the ogre becomes the feminine literary strategic expression of female power in opposition to male dominance.

Ngugi Wa Thiong'o' version of this and the other folktales adopted in the text offer an extended interpretation depicting the feat of overcoming the ogres as a collective and collaborative effort between the men and the women. Overcoming Mwengeca runs beyond the psychosexual and the 
psychosocial maturation of the girls. In the traditional story the healing element is the leaf at the tip of the tree that grows in the center of Mwengeca's garden. This, in the Freudian sense avers to the phallic extension. To attain maturation and overcome the male world, the girl must overcome her desire for the phallic and be able to use that desire for her own ends. In Ngugi Wa Thiong'o' narrative, the healing element is on the tongue of the ogre. The nine daughters and their suitors, led by Wanjiru, retrieve the healing hair and mutilate the ogre's tongue into nine strands. Symbolically, by cutting off the strand of hair at the tip of the ogres tongues, they free themselves from the bondage of foreign languages in Africa and the yoke of and cultural and economic imperialism, which have ravaged Africa since the advent the trans-Atlantic slave trade. By retrieving the healing hair from the tongue of the 'ogre', then Africa can rise from the infirmity of 'the postcolonial' as Warigia rises from her infirmity the moment the ogres tongue is shredded.

The encounter with the 'Ogre of Darkness that never ends' (Gitumagitatumukaganduma) symbolically foregrounds the struggle in Africa with the forces that for centuries have aligned themselves with the foreigners. Their mission is to create and perpetuate Africa as 'the heart of darkness.' This ogre represents the continuation of the racist and imperialist mission. The ogre's task is to ensnare the souls into great darkness, lead them into the ways of darkness without salvation and capture them for his master, the chief of the ogres. As he captures for the master, he also captures some for his meals. For now, he would let all the others go scotch free if they hand over Wangari to satiate his appetite. But Wangari, 'she who is of the leopard' is not afraid of this 'Great Darkness'. Her eyes, she proclaims, are those of the leopard and penetrates darkness like the sun during daylight or like the full moon during the night' (80-81). Using the flint stones in her bag, she lights a torch instantly holding the ogre of darkness at bay. The others follow suit and with lit torches they chase away the ogre. In sadness, they celebrate the rising sun the following morning as three of their companions have been killed by this ogre.

The "Ogre of Spitting Fire" (Gicinagiciniriri) exhales fire though the nostril and mouth devastating the entire vegetation within its vicinity. For now he needs to be placated with Mwithaga to let the others go. But he is no match for Mwithaga, who is also Nyambura or Wambura the rain maker. She leads the troop up unto the safety of the Mugumo tree, the perpetual shrine of the God of Gikuyu and Mumbi. From here, she causes rain to fall vanquishing and expelling the 'The Ogre of Spitting Fire'. 'The ogre (ogres) of 'the basket that that never fills up' on the other hand wants to be offered Wairimu, to be left behind and become his wife if the rest will proceed back home.

In confronting this ogre, Wairimu is keen and observes that while the ogre has eyes both in front and at the back of the head, he is not capable of a third dimension vision. She climbs on top of a tree and attacks from above forcing the ogre to flee in pain.

The binary oppositions continue with other ogres sent by Mwengeca: the 'Ogre of Eternal Tears', the 'Ogre of Unending Defecation' and the 'Ogre of Bloody Lips'. The last ogre relishes in sucking the blood out of the bodies of human beings, leaving them but empty shells. Among the many others ogres encountered is the one who could remove body organs, washes them, and lays them out to dry and fix them back to the body at will, and another two who transform themselves into a hyena and crow respectively. The last of the ogres, who are both male and female, seek to capture the girls and their suitors through an alluring beauty of their fake bodies only to be exposed by a strong winds to be bare skeletons. These ogres remind us of Amos Tutuola's 'perfect gentleman' in the Palm Wine Drinkard and constitutea common motif in African folktales of the handsome suitor who attracts girls during dances only for them later to discover he is an ogre. This motif has been used by Ngugi Wa Thiong'o cross-textually to critic the 'African' fascination with the 'white aesthetic', western culture and foreign languages as superior than their own.

The ogres are defeated with the opposite forces that nature and sustain humanity confirming that persistent endurance and innovative reaction against negative forces will eventually lead the people to overcome. In the confrontation with the ogres, the text reflects on the African journey through time, especially the destructive forces of secessions, irredentism, military coups dictatorships and environmental destruction during the post-independence period. The lesson for 'The Perfect Nine' is that ogres are not but fireside fantasies but are real, evil and destructive and should be fought all the time (p.102). However, overcoming the ogres in the text is not a final eradication of the forces against Africa. The child ogre, Manga, proclaims to his father during the final escape that he is unscathed and he will procreate more ogres to continue and perpetuate the 'ogre agenda' (p.95). 
By retracing the journey to the mountain top, to the abode of God of Gikuyu and Mumbi, the suitors from all corners of Africa fuse with Gikuyu, Mumbi and their daughters into the permanence of the Gikuyu nation in 'the perfect nine'. The journey is a collective and individual challenge for endurance, courage and a test of inner strength for social survival. It represents the struggles of life, becoming a journey of self-awareness and self-awakening for those who will form the Kikuyu nation. Ten of the suitors and all the nine daughters make it, bringing back their gourds of the water from the 'pool of God' and the melted ice from top of Mount Kirinyaga to be born again into the future Kikuyu clans consisting of the perfect nine.

\section{Warigia, 'The Perfect Ninth'}

As mentioned earlier, Warigia the last born daughter of Gikuyu and Mumbi is the tenth daughter, but traditionally, always muted in as the 'full nine' (Kenda Muiyuru). Tradition has it that she got pregnant outside wedlock and never got married. She became the progenitor of the tenth clan, The Aicakamuyu clan. Ngugi Wa Thiongo'o' Warigia (Wamuyu) is a completely remodeled heroine. Like Sudiata in the Epic of Old Mali, she is unable to walk in childhood. And her infirmity is one of the key conflict that motivates action in this narrative. One of the key mission and test of the suitors in the journey retracing the footsteps of the Gikuyu and Mumbi is to bring back the only medicine that can cure her lameness. It is only after the healing strand of hair is cutoff and procured from the tongue of the ogre Mwengeca that she instantaneously heals and is able to walk.

But even in her previously infirmity, she had mastered the skill of archery. She invites herself into the competition mounted by her parents for the daughters and the suitors and emerges the overall winner. She is decisive. While her sisters are fighting over the ninety nine men she has already selected her partner. When her man, Kihara, the one who cut the 'healing hair' refuses to live in Gikuyu and Mumbi's compound and opts to go back home, she follows him against her father's verdict. But as fate would have it, a lion attacks before they reach Kihara's home. The Lion fatally wounds Kihara, who advises her to return home as he dies. She hunts down the lion and returns home pregnant with Kihara's child to join the others in the final rituals to constitute the perfect nine.

Kenda Muiyuru, Rugano Rwa Gikuyu Na Mumbi (The Perfect Nine: The Epic of Gikuyu and Mumbi)is presented in a shifting point of view, beginning with the omniscient narrator who indicates the story as a 'revelation', 'that came with the wind as he sat on the hill watching swallows gliding in the air' (P. xii,8). This voice authoritatively presents the background, offering the reader authentic information, knowledge and interpretation of the story of Gikuyu and Mumbi. The voice connects the Kikuyu with other nations in time and space and the environment in which they exist. Once the mission to the mountain begins, the narrative perspective shifts to first person voice which presents a participant's and a witness account of the marvelous adventure of the group retracing the footsteps of Gikuyu and Mumbi. This first person narrative is the voice of 'the perfect nine' relieving their experience during the epic journey to their parents. While this narrative adopts the epic style, the story lacks a central hero of the traditional epic. Action and resolution here rests on the communal hero in the ten daughters and the men who seek their hand in marriage.

\section{CONCLUSION}

The fashioning of this epic offers validation of the existence of Kikuyu and gives the author the platform to interrogate African history, African aesthetics and the general essence of human existence. Nevertheless, this work departs from the writer long history as a social and political novelist. All his earlier narratives, The River Between, Weep Not Child, a Grain of wheat, petals of Blood, Devil on the Cross, Matigari, Wizard of the Crow and the children series of Njaamba Nene focus on social and political themes in postcolonial Kenya and Africa. In Kenda Muiyuru, Rugano Rwa Gikuyu na Mumbi (The Perfect Nine: the Epic of Gikuyu and Mumbi), Ngugi Wa Thiong'o re-fashions a popular cosmogonic myth into a forceful symbolic narrative of victory, hope and continuity of the African space and ethos

Ngugi's rendition in this narrative becomes a metaphor for an African renaissance, the re-emergence of a great African nation that can only be achieved by retracing the steps to the beginning. The return to the primordial times, travelling the road of the fore parents may occasion the recreation of a stable and just Africa. This return is instrumental for African to defeat the jinx of the cycles of ogre exploitation and destruction of the continent.In the process, the narrative presentsNgugi's ultimate feminist vision that proposes gender equity as the base for the creation of a stable self-sustaining, just, equitable and a prosperous society. 


\section{REFERENCES}

[1] Amuka, Peter. 'Oral Literature and Fiction.' In Ochieng, William. (Ed.) 1990. Themes in Kenyan History. Nairobi: Heinemann Educational Books

[2] Dundas, K R. 1908: 'Notes on the origins and History of the Kikuyu' in ManVol. 81908

[3] Castro, Peter. 1995. Facing Kirinyaga: A Social History of Forest Commonsin Southern Mount Kenya. London: Intermediate Technology

[4] Kenyatta, Jomo. 1978 (1938). Facing Mt. Kenya. Nairobi: Heinemann Educational Books

[5] Lambert, H.E. 1956. Kikuyu Social and Political Institutions. London: Oxford University Press

[6] Macgregor, A. W.1909. 'Kikuyu and Its People', Church Missionary Review.Vol. 60 London: Church Missionary Society

[7] Muriuki, Godfrey. 1974. A History of the Kikuyu. 1500-1900. Nairobi: Oxford University

[8] Mutahi, Karega. 1983 (1977). Sound Changes and the Classification of the Dialects of Southern Mt. Kenya. Berlin, D. Reimer

[9] Ngugi Wa Thiong'o .1962. The River Between. London Heinemann Educational Books.

[10] ................... 1965. Weep Not Child. London. Heinemann Educational Books

[11] .................... 1967. A Grain of Wheat. Nairobi. Heinemann educational Books

[12] ................... 1977. Petals of Blood. Nairobi. Heinemann Educational Books

[13] .................... 1982. Devil on the Cross. Nairobi Heinemann Educational Books.

[14] ..................... 1984. NjaambaNeenenaMbathi Iii Mathagu. Nairobi EAEP.

[15] ........................ 1964.Njaamba Neene na Cibu King'ang'i. Nairobi EAEP.

[16] ......................... 1985 Mbathitora Ya Njaamba Nene. Nairobi EAEP.

[17] .................. 1986Matigari. Nairobi Nairobi. EAEP.

[18] ................... 2008. The Wizard of the Crow. Nairobi EAEP.

[19] ....................2018. Kenda Muiyuru, Rugano Rwa Gikuyu Na Mumbi. Nairobi EAEP

[20] Ogude, James. 1999. Ngugi's Novels and African History: Narrating the Nation.

[21] London: Pluto Press.

[22] Sanday, Peggy Reeves. 1981. Female Power, Male Dominance: On the Origins of Sexual Inequalities. London: Cambridge University Press.

[23] Waita, Njogu 2019. Literary Communication: Oral Literature, Change and innovations in Kenya. Nairobi/Kerugoya, Kairos Publishers.

[24] Kabira, Wanjiku. 2019. Interview with WanjikuMaina, Daily Nation $12^{\text {th }}$ Feb, 2019

[25] Kabira, Wanjiku\&Waita, Njogu (Eds). 2010. Reclaiming My Dreams. The Narratives of Wanjira Wa Rukenya. Nairobi. Nairobi University Press.

\section{AUTHOR'S BIOGRAPHIES}

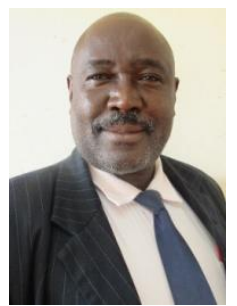

Prof. Njogu Waita, holds a $\mathrm{PhD}$ in African languages and Literatures from the University of Cape Town and a Bachelors and Master's degrees in literature and a postgraduate diploma in Mass communication and Journalism from the University of Nairobi. He has published widely in areas of African literature (oral and written), gender, African languages and media studies. Prof. Waita has over 30 years university teaching and research experience having taught at the University of Nairobi, Moi University, Egerton University, Laikipia University and Chuka University, all in Kenya. Presently he is teaching literature and media studies at the Department of Humanities in Chuka University. Professor Waita has also worked as a reporter and editor for the Kenya Broadcasting Corporation.

Citation: Njogu Waita. "Ngugi wa thiong'o's Cosmogenic Meta-Myth in The Perfect Nine: The Epic of Gikuyu and Mumbi (Kenda Muiyuri: Rugano Rwa Gikuyu Na Mumbi)" International Journal on Studies in English Language and Literature (IJSELL), vol 8, no. 7, 2020, pp. 28-34. doi: http://dx.doi.org/10.20431/23473134.0807004.

Copyright: (C) 2020 Authors. This is an open-access article distributed under the terms of the Creative Commons Attribution License, which permits unrestricted use, distribution, and reproduction in any medium, provided the original author and source are credited. 